\title{
Helicobacter pylori Infection and Reproductive Disorders
}

\author{
Natale Figura ${ }^{1}$, Giulia Collodel ${ }^{2,3}$ and Elena Moretti*,2,3 \\ ${ }^{I}$ Department of Internal Medicine, Endocrine-Metabolic Sciences and Biochemistry; ${ }^{2}$ Department Biomedical Sciences, \\ Applied Biology Section; ${ }^{3}$ Interdepartmental Centre for Research and Therapy of Male Infertility, University of Siena, \\ Siena, Italy
}

\begin{abstract}
We propose to determine routinely the existence of an $H$. pylori infection in men and women with reduced fertility. Our proposal is based on the following observations: a) the infection is more prevalent in patients than controls, b) the infection could negatively affect semen quality, c) the presence of $H$. pylori influences the levels of inflammatory cytokines in the blood stream and stimulates the production of antibodies that, being also present in follicular fluids, vaginal mucous and semen of infected people, could possibly hamper the meeting of sperm with the oocyte.
\end{abstract}

\section{LETTER}

Reproductive disorders are steadily increasing. Figura et al., [1] proposed $H$. pylori infection as a possible concomitant cause of reduced fertility and sperm damage: the infection is significantly more common in both men and women with trouble procreating; infected individuals have specific antibodies in semen, follicular fluid and vaginal secretions, which may cross react in vitro with spermatozoa, suggesting the existence of autoimmune phenomena; the amino acid alignment of the human tubulin, a major sperm flagellar constituent, with $H$. pylori peptides may indicate the existence of an antigenic mimicry with the cytotoxinassociated gene A protein (CagA) and other H. pylori antigens.

Other groups have shed new light on this topic. Kurotsuchi et al., [2] found that $H$. pylori infection was twice as prevalent in women with procreation problems, in whom the search for the most common causes of reduced fertility had yielded negative results. Ambrosini et al., [3] have recently found that in vitro sperm motility through cervical mucous was significantly reduced in infected women and they concluded that anti-H. pylori antibodies could possibly hamper the meeting of sperm with the oocyte. These findings suggest that $H$. pylori infection, in both men and women, could contribute to decrease the probability of pregnancy.

These observations are derived from solid bases of biological plausibility: $H$. pylori infected men, especially those with serum antibodies to the CagA protein (i.e. that they are infected by bacterial genotypes endowed with an increased inflammatory potential), have a) increased systemic levels of tumor necrosis factor-alfa, a proinflammatory cytokine that may cause sperm damage; $b$ ) reduced sperm motility in vitro and c) a greater number of necrotic and apoptotic spermatozoa in their ejaculates [4]. The partial results of still another unpublished study from

*Address correspondence to this author at the Department of Biomedical Sciences, University of Siena, Policlinico S. Maria alle Scotte, V.le Bracci, 53100 Siena, Italy; Tel: +39 0577 233511; Fax: +39 0577 233527;

E-mail: mailto:elena.moretti@unisi.it our group show that $H$. pylori infection may regulate the seminal levels of ghrelin, a hormone endowed with antiinflammatory properties [5] and involved in reproduction [6], suggesting that the infection may influence the semen concentration of hormones. We therefore believe that there are enough indications that $H$. pylori infection should be listed among the putative causes of reduced fertility in males and females.

Assuming that the infection increases the risk of infertility, why in the developing countries, where practically everyone is infected, has the birth rate steadily risen? In European and American countries, H. pylori causes a predominant and prolonged Th1-type response, which is unable to eliminate the organism, damages the gastric mucosa and increases the systemic inflammatory status. As an additional possible consequence, high levels of proinflammatory cytokines may injure extra-digestive organs, including the reproductive apparati [7, 8]. In developing countries, the endemic helminthiasis and other parasitic infestation change the Th-cell immune response from a predominantly Th1-type to a Th2-type, which is considered protective and is characterized by the release of the non-inflammatory cytokines IL-4, IL-5, IL-6 and IL-10 [9]. The results of a study performed in Colombian children, for instance, suggest that intestinal helminthiasis promotes Th2-polarizing responses to $H$. pylori and reduces the mucosal damage caused by the inflammation; the decreased inflammatory status is reputed to prevent the progression of gastritis to gastric atrophy, dysplasia, and cancer [10]. Studies performed in animals, experimentally infected by $H$. pylori and parasites, have confirmed the observations made in humans; in particular the production of anti-inflammatory cytokines triggered by parasitic infestation could protect the gastric mucosa $[11,12]$. Protection may have systemic effects: the release of anti-inflammatory cytokines due to the Th2 response may counteract the deleterious effects of inflammation and possibly spare the involvement of extradigestive organs, and fluids, such as the ejaculate.

In conclusion, we propose that individuals with reproductive disorders should be routinely examined for $H$. pylori infection and anti-CagA serum antibodies. Ultimately, 
putative recognized causes of decreased fertility can be found in only half the couples who are referred to fertility clinics.

\section{ACKNOWLEDGEMENT}

None declared.

\section{CONFLICT OF INTEREST}

None of declared.

\section{REFERENCES}

[1] Figura N, Piomboni P, Ponzetto A, et al. Helicobacter pylori infection and infertility. Eur J Gastroenterol Hepatol 2002; 14: 6639.

[2] Kurotsuchi, S, Hisao Ando H, Iwase A, Ishida Y, Hamajima N, Kikkawa F. The plausibility of Helicobacter pylori-related infertility in Japan. Fertil Steril 2008; 90: 866-8.

[3] Ambrosini G, Andrisani A, Fiore C, et al. Anti-Helicobacter pylori antibodies in cervical mucus: a new cause of infertility. Eur $\mathrm{J}$ Obstet Gynecol 2011; 155: 157-60.

[4] Collodel G, Moretti E, Campagna MS, Capitani S, Lenzi C, Figura N. Infection by CagA-positive Helicobacter pylori strains may contribute to alter the sperm quality of men with fertility disorders and increase the systemic levels of TNF-alpha. Dig Dis Sci 2010; 55: 94-100.

[5] Taub D. Novel Connections between the Neuroendocrine and Immune Systems: The Ghrelin Immunoregulatory Network. Vitam Hor 2008; 77: 325-46.

[6] Repaci A, Gambineri A, Pagotto U, Pasquali R. Ghrelin and reproductive disorders. Mol Cell Endocrinol 2011; 340: 70-9.

[7] D'Elios MM, Andersen LP, Del Prete G. Inflammation and host response. Curr Opin Gastroenterol 1998; 14: 15-9.

[8] Bamford KB, Fan X, Crowe SE, et al. Lymphocytes in the human gastric mucosa during Helicobacter pylori have a T helper cell 1 phenotype. Gastroenterology 1998; 114: 482-92.

[9] Gordon D. Solving the African enigma: parasites may have their place. Gastroenterology 2000; 119: 611.

[10] Whary MT, Sundina N, Bravo LE, Correa P, Quinones F, Caro F, Fox JG. Intestinal helminthiasis in Colombian children promotes a Th2 response to Helicobacter pylori: possible implications for gastric carcinogenesis. Cancer Epidemiol Biomarkers Prev 2005; 14: $1464-69$

[11] Fox JG, Wang TC, Nagler-Anderson C. The African enigma: the parasite's perspective. Gut 2001; 49: 156-7.

[12] Mitchell HM, Ally R, Wadee A, Wiseman M, Segal I. Major differences in the IgG subclass response to Helicobacter pylori in the first and third worlds. Scand J Gastroenterol 2002; 37: 517-22.

This is an open access article licensed under the terms of the Creative Commons Attribution Non-Commercial License (http://creativecommons.org/licenses/by-nc/3.0/) which permits unrestricted, non-commercial use, distribution and reproduction in any medium, provided the work is properly cited. 